Original Contribution

\title{
IDENTIFYING THE DEMANDS OF THE LABOUR MARKET IN THE STARA ZAGORA REGION, WITH REGARD TO THE TUITION OF SPECIALISTS WITH HIGHER ECONOMIC EDUCATION
}

\author{
V. Gaydardzhieva*, Y. Yarkova, Iv. Georgiev, R. Otuzbirov
}

Faculty of Economics, Trakia University, Stara Zagora, Bulgaria

\begin{abstract}
Best indicators of economic development and education in the region constitute a sound basis for regional studies of national importance in improving business interaction - education and preparation of the necessary specialists to practice. The main objective of this study is to identify the demands of the labour market in the region on the professional training of students in the field of economics, management and regional development based on the current curricula in the Faculty of Economics (SF) Trakia University. Object of research are representatives of the practice - business and public entities - potential employers of professionals trained in Faculty of Trakia University. The study focused on issues related to the provision of practical training of students and training geared to the needs of employers. Expected by conducting survey and its analysis to contribute to improving the quality of education and training of economists, a new type of competitive labour market, meeting the needs of business and practice in Stara Zagora region.
\end{abstract}

Key words: economic development, labour market, regional development, professional training of students in the field of economics

\section{INTRODUCTION}

The Stara Zagora region is an affirmed hub for business and higher education of national significance. The Stara Zagora region belongs to the Southeast planning region (NUTS level 2) and includes 11 municipalities with a scope of 206 populated areas. The population (2011) is 332340 people, and employment rate (211) was 45.1\%. GDP per capita (2000) was BGN 9207 (1). The rating chart of regions according to social-economic development for the period 2007 - 2010 place Stara Zagora in the group of regions exhibiting improvement (2). The evaluations of the economic and business environment in the region are fairly high, compared to the other regions.

The region has traditionally high production rates and a well-developed heavy industry. The Stara Zagora region is distinguished with the fourth highest production per capita, which is mostly due to large companies in the field of

*Correspondence to: Assoc. Prof. Veneta

Gaidardjieva, PhD, Faculty of Economics, Trakia

University, Stara Zagora, Bulgaria, Phone: +359

42699 402, E-mail:veng.sz@abv.bg power production, such as the "Maritsa-Iztok 2" thermal power plant and the "Mini Maritsa Iztok" coal mines. The rates of employed persons within the region for the period $2000-$ 2009 are also at high levels and rank behind the regions of Russe, Varna, Blagoevgrad and Sofia (capital city), yet they dropped as a result of the economic crisis in 2010 - 2011.

The region is distinguished with a relatively low number of companies with regard to the population, yet this is due to the several large companies, which provide employment to many workers. The number and size of the companies have a positive influence on the volume of foreign investments in them, which are at a relatively high level.

The absorption of European funds per capita for projects by the municipal administrations in the region is the second highest in the country after Sofia (capital city). The evaluation of the region's business environment is one of the highest in the country, ranking behind regions such as Russe, Vratsa, Targovishte. The region is 
distinguished with its low local taxes, which are among the 10 lowest in the country.

The number of university students per capita in the region is relatively low, yet Trakia University is located within the district centre and it has the largest faculties of agriculture and veterinary medicine in the country. During the period 2000 - 2011, the number of students within the region increased by more than $60 \%$. The Faculty of Economics, which was opened in 2009, holds leading positions among the economic faculties within the country in terms of number of students applying for a spot. The capacity of tutored students of economics has increased nearly 2.5 times over the last five years (2009-2014).

The good indicators for economic and educational development within the region represent a solid base for regional research with national significance, with regard to improving the interaction between business and education and the preparation of the specialists needed in practice.

The primary objective of the present study is to identify the needs of the employers within the region with regard to the professional training of students in the field of economics, management and regional development on the grounds of the current curricula and programmes at the Faculty of Economics (FE) of Trakia University.

The subject of study is representatives of practice - business and public structures potential employers of the specialists trained at the Faculty of Economics at Trakia University.

The object of study is the problems related to providing a practical training of students and qualification aimed at the employers' necessities.

The expectations are to contribute, by conducting a survey and analysing its results, towards increasing the quality of education and the preparation of a new type of economists, who would be competitive on the labour market, responding to the demands of business and practice within the Stara Zagora region. We believe that only through the building of a longterm cooperation between academic institutions, business and governance can we achieve the goal of intelligent growth on a national and regional level. The course of economic development and the type of society that we are building today determine the nature of the relations and models of interactions among the representatives of a community (3).

The survey was conducted in 2013 as a part of a project by the Faculty of Economics: "Updating the current curricula and study programmes, and development of new ones in the professional directions of 3.8 «Economics» and 3.7 «Administration and management» at the Faculty of Economics, Trakia University, in accordance with the needs of the regional labour market in the Stara Zagora region" http://auppisf.eu per Agreement BG051PO001-3.1.07-0014, non-refundable financial aid provision scheme BG051PO001-3.1.07 „Updating the curricula in higher education, in accordance with the requirements of the labour market," Operative programme „Human resources development.”

\section{RESULTS AND DISCUSSION}

For Activity 1 of the project: Identifying the necessities and requirements of the labour market with regard to the majors at the Faculty of Economics (FE), 36 meetings and surveys were conducted with employers and specialists from practice.

The choice of companies and institutions was coordinated with the following:

- Compliance with the majors that students pursue at the Faculty of Economics

- The structure of economic activities in the Stara Zagora region in the non-financial sector (commerce, processing industry, harvesting/gathering industry, energy production, construction, agriculture)

The survey encompassed:

- Public institutions (state institutions, employer associations, etc.) - 14

- Non-financial ventures from the fields of: commerce, processing industry, harvesting/gathering industry, construction, agriculture -17

- Financial ventures - 3

Structure of the private companies included into the survey:

- $\quad$ Micro (below 10) - 3

- Small (below 50) - 5

- Medium (below 250) - 7

- $\quad$ Large -5

The survey consisted of 26 questions and a demographic block, with the questions being divided into the following groups: 
GAYDARDZHIEVA V., et al.

- Difficulty level of finding specialisteconomists and searching for economists who have completed majors at the FE, TrU;

- Readiness for and form of admitting students into practices and internships;

- Readiness for participation under various forms in the academic and scientific research activities, including through concluding a cooperation contract;

- Criteria for selection of specialisteconomists;

- Evaluation of the current curricula and study programmes at the FE;

- Recommendations for the improvement of the academic content and improvement of practical training.

\section{Types of questions in the survey:}

Dichotomy question - a question with two possible answers.

Multiple-answer question

Likert scale type questions - they determine the extent of agreement (4)

Significance scale - scale related to ranking a certain concept in terms of its importance in the mind of the user.

Rating scale, examines the degree of approval

The surveyed persons' responses indicated that $85.3 \%$ of them occupied managerial positions and had a clear idea of the overall process of management, development and the need for staff potential at the company (institution)

(Figures 1 and 2):

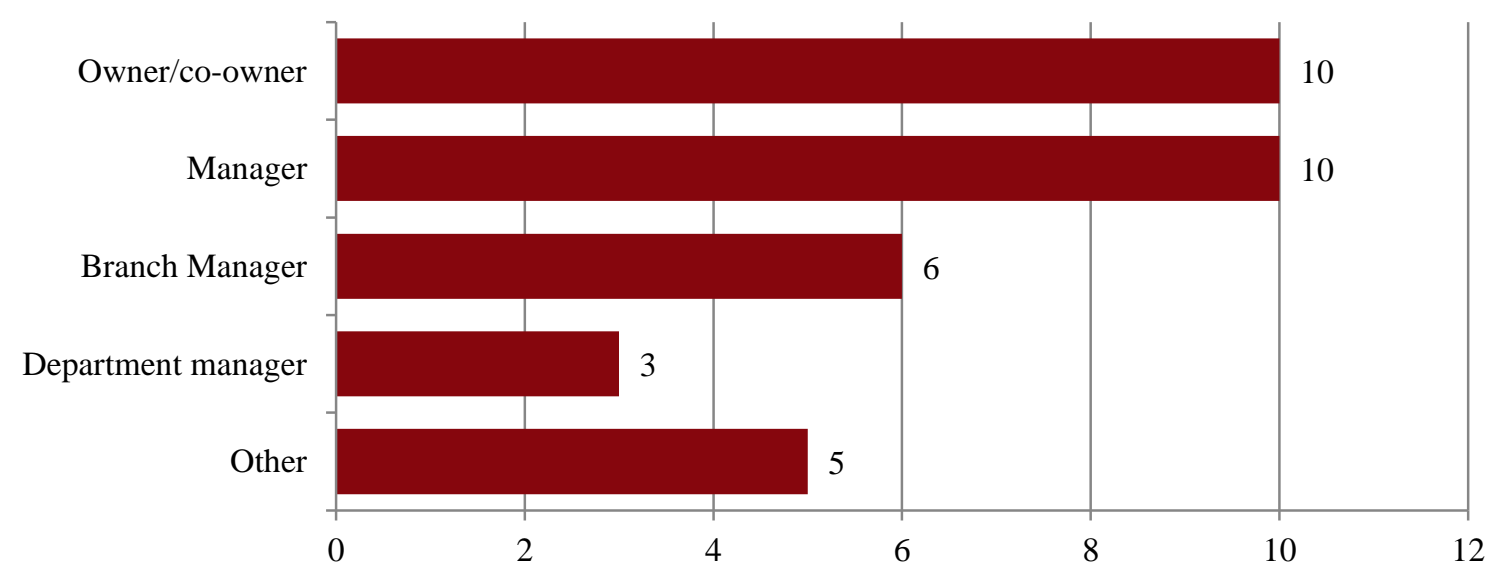

Figure 1. Occupied position within the firm/organisation /Respondents: $34(100 \%) /$

The predominant number of surveyed persons, $76.6 \%$ work at companies founded more than 24 years ago. This allows for more accurate assessments, based on the respective institutions' experience and traditions:

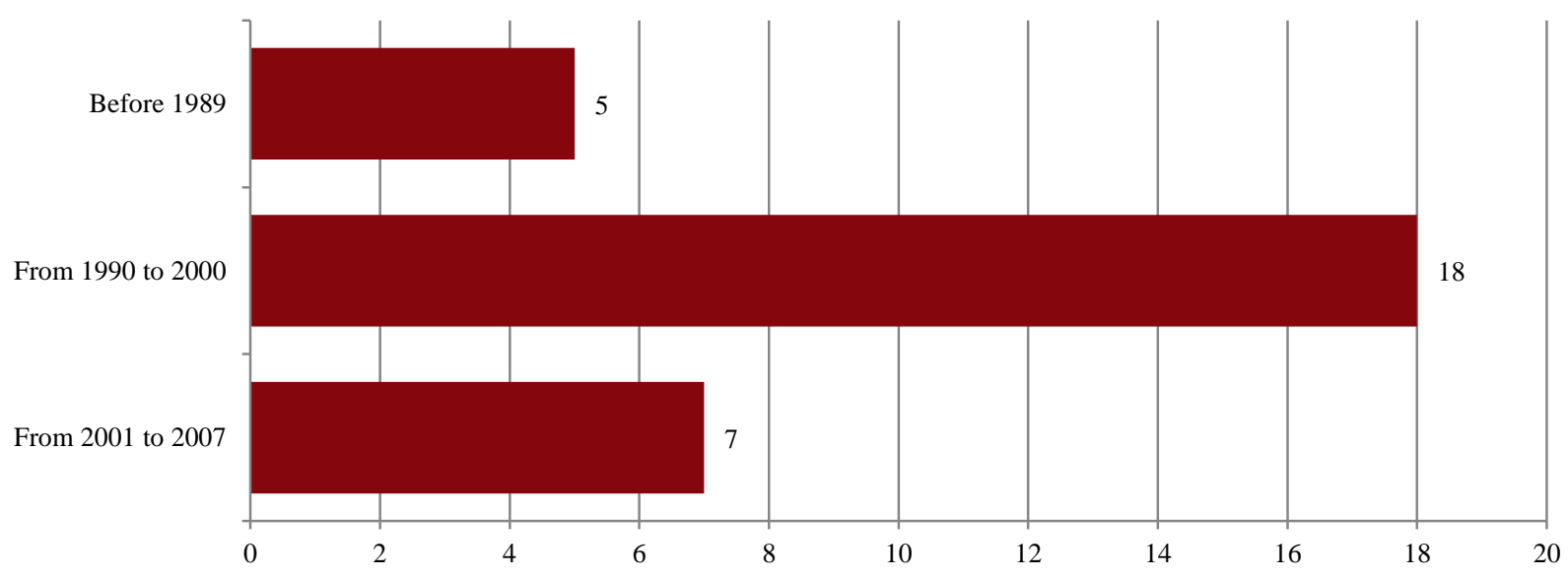

Figure 2. Year of founding the firm/institution /Respondents: 30 (88.24\%)/ 
The respondents exhibited increased interest towards the topic of the study and replied to the questions the following way:

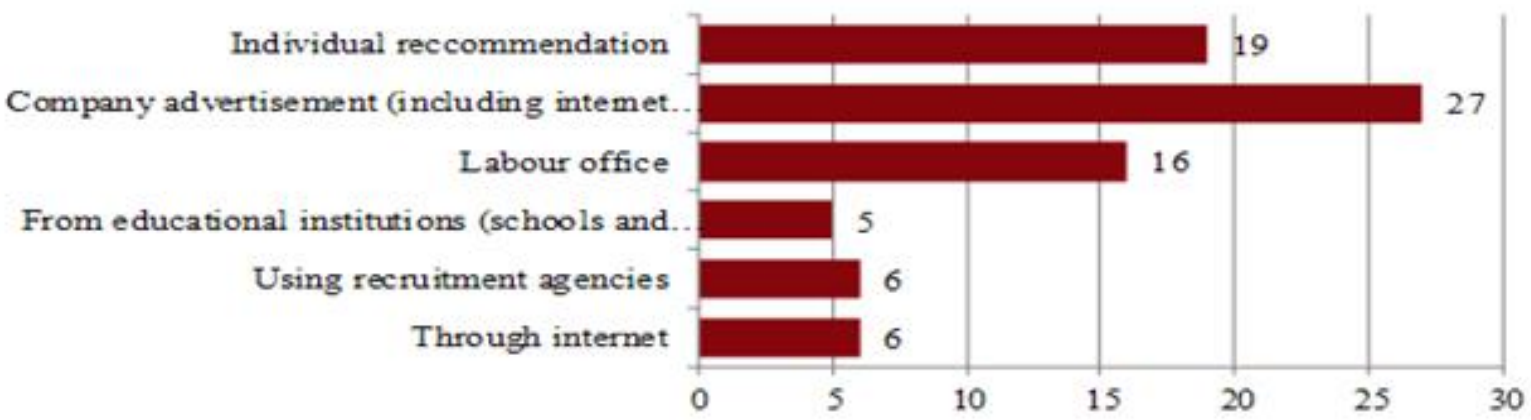

Figure 3. Question 1 - How do you select new employees at your firm/institution? /Respondents: 33 (97.06\%)/

While selecting new employees, companies usually preferred public announcements through the official information sources and institutions (Figure 3). Personal contacts and networking were also preferable. Only $6.3 \%$ of all respondents relied on established contacts for cooperation between educational institutions and business organisations (For most of the questions, the sum of all replies was greater than 34 , i.e. the respondents chose more than 1 option).

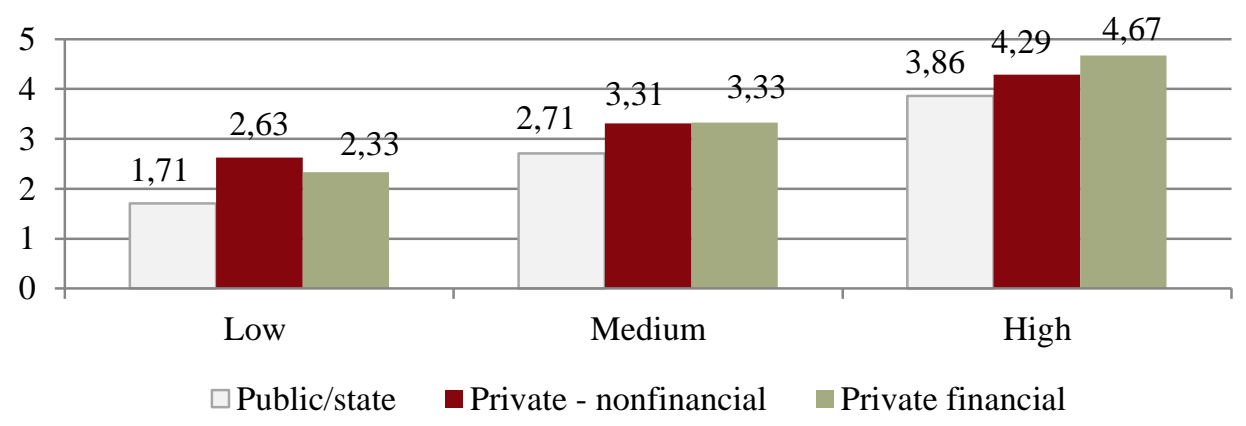

Figure 4. Question 2. On a scale of 1 to 5, determine how easy or difficult you find the specialist economists that you need, with "1" standing for "very easy" and " 5 " standing for "very hard" /Respondents: $34(100 \%) /$

According to the respondents, the higher criteria for the selection of specialist-economists are placed in the private sector (Figure 4). The criteria for higher positions are proportionally increased in the public, as well as the private sector.

Low overall level of education in the country Insufficient qualification

Education fails to meet market requirements Low mobility within the country Influx of emigrants No difficulties

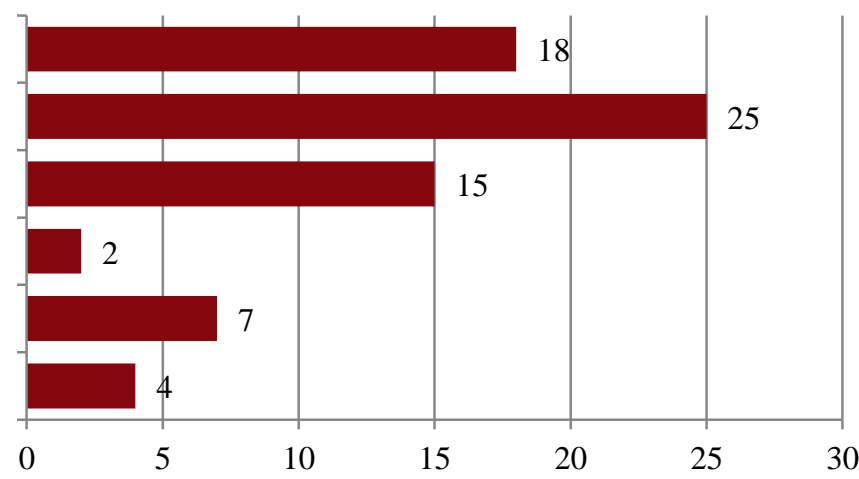

Figure 5. Question 3. How do you explain the difficulties in finding the specialist-economists that you need? /Respondents: $34(100 \%) /$ 
The respondents (Figure 5) indicated the insufficient level of qualification, as well as of general education and vocation training, were the
GAYDARDZHIEVA V., et al.

main problems while finding well-trained specialists.

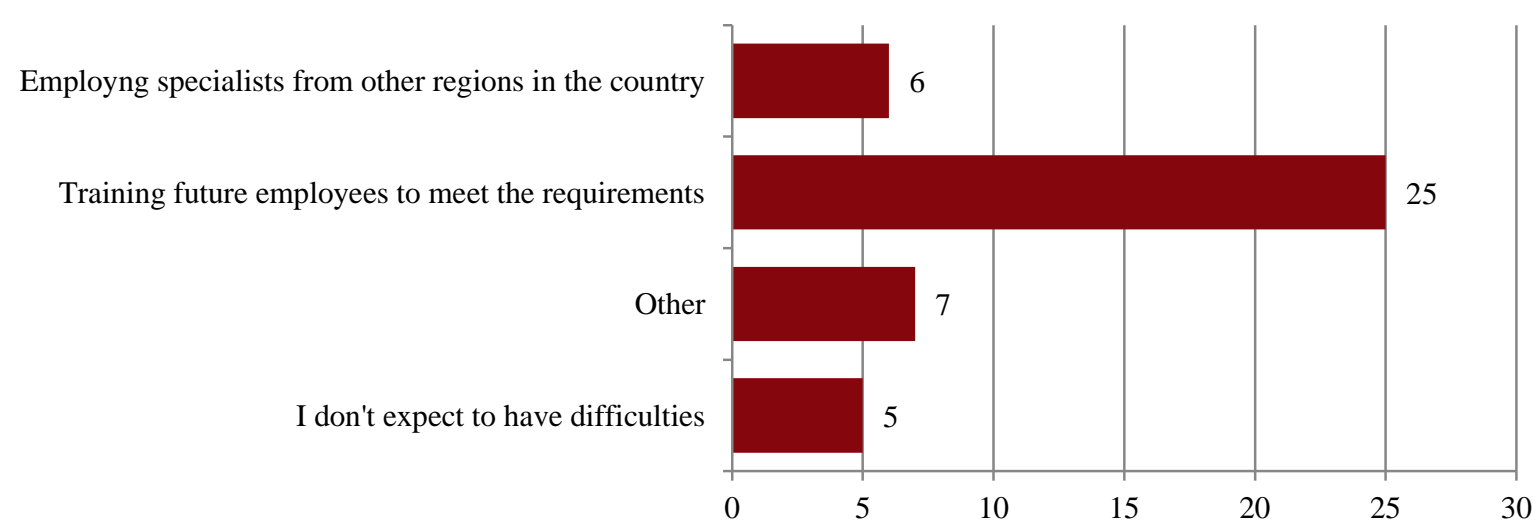

Figure 6. Question 4. How would you solve the problems with the finding of specialists with suitable qualities and skills? /Respondents: 31 (91\%)/

In 25 of the responses (Figure 6) from a total of 43 (or in $58.1 \%$ ) the employers declared their readiness to train the specialists they need. With these attitudes, we could predict a trend towards mutual interest in closer cooperation between educational and production organisations.

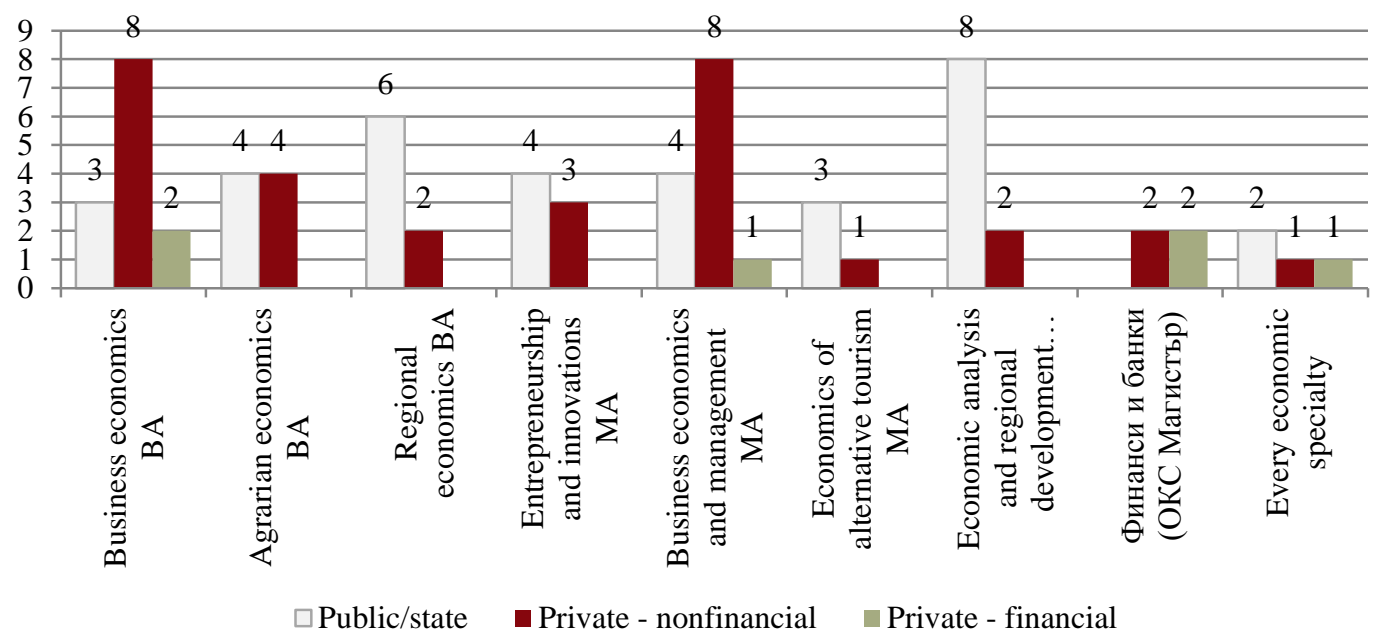

Figure 7. Question 5. For which majors could your firm/institution offer job positions to the students graduating from the Faculty of Economics (FE) of Trakia University (TrU)? /Respondents: 34 (100\%)/

With regard to the realisation of the students in the majors offered in the educationalqualification degree of "Bachelor" and "Master" at the FE of Trakia University (Figure 7), public sector companies' and institutions' interests are as follows:

- $\quad$ in the state sector there is an apparent demand for specialists in regional economics, which is due to the increase in the activity of regional and local structures in their work with European and national strategies and plans for regional policy and development. There is an increased interest towards Masters in Regional Studies;

- in the private non-financial sector, the highest interest is towards the specialists in "Business economics" for the educationqualification degree of "Bachelor" and "Economics and management of business" for the educational-qualification degree of "Master";

- a weaker interest is exhibited towards the student-economists of the FE by the private 
financial sector. This is because the education at the faculty is oriented towards the training of specialists in agricultural economics, regional economics and business economics. There is an interest towards students in the major "Finance and banking."

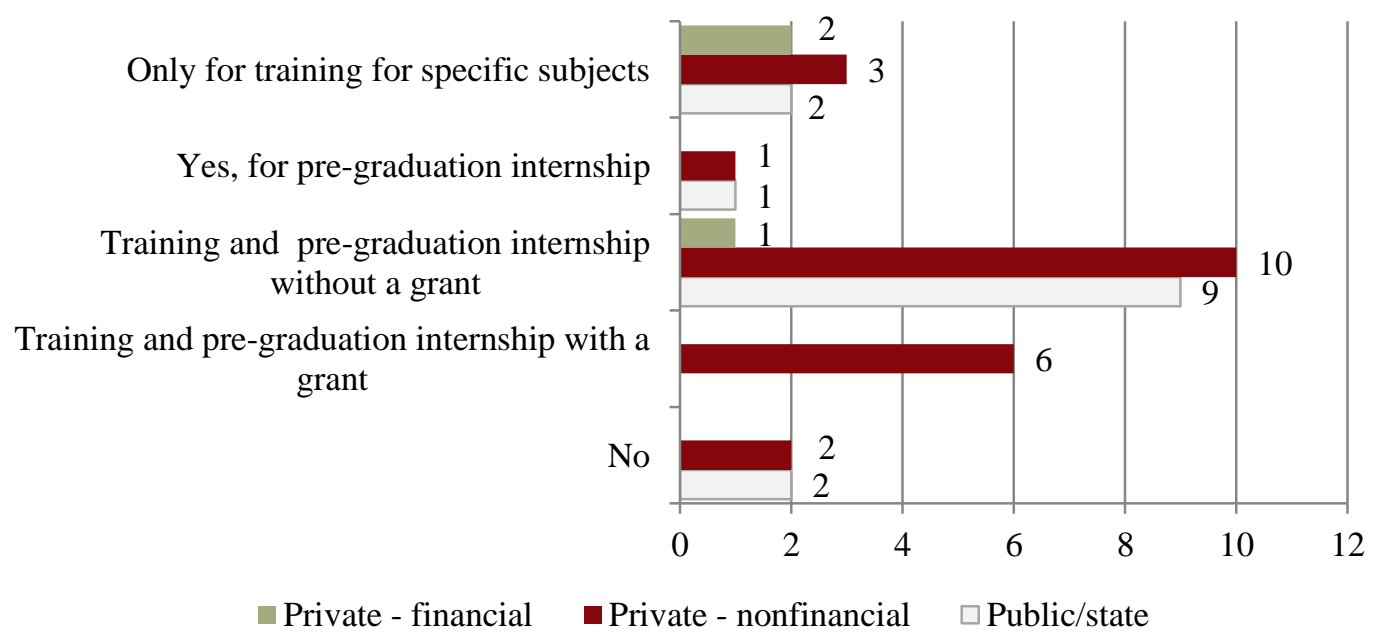

Figure 8. Question 6. Would you provide an opportunity for conducting practical exercises and internships for the students from the Faculty of Economics at TrU within your firm/institution? /Respondents: 34 (100\%)/

The attitude of business and practice are to be involved in the practical training of students, yet without taking on more constructive engagements and responsibilities, especially with regard to paying for the students' labour. Only in $15 \%$ of the responses (Figure 8) there was an overt wish by business to provide financial support to students.
The public sector is not prone to make such engagements. The local public administration has a major need for trained specialist in Regional Studies, yet it is probably unable to overcome the bureaucratic customs in order to attract and specialise such professionals.

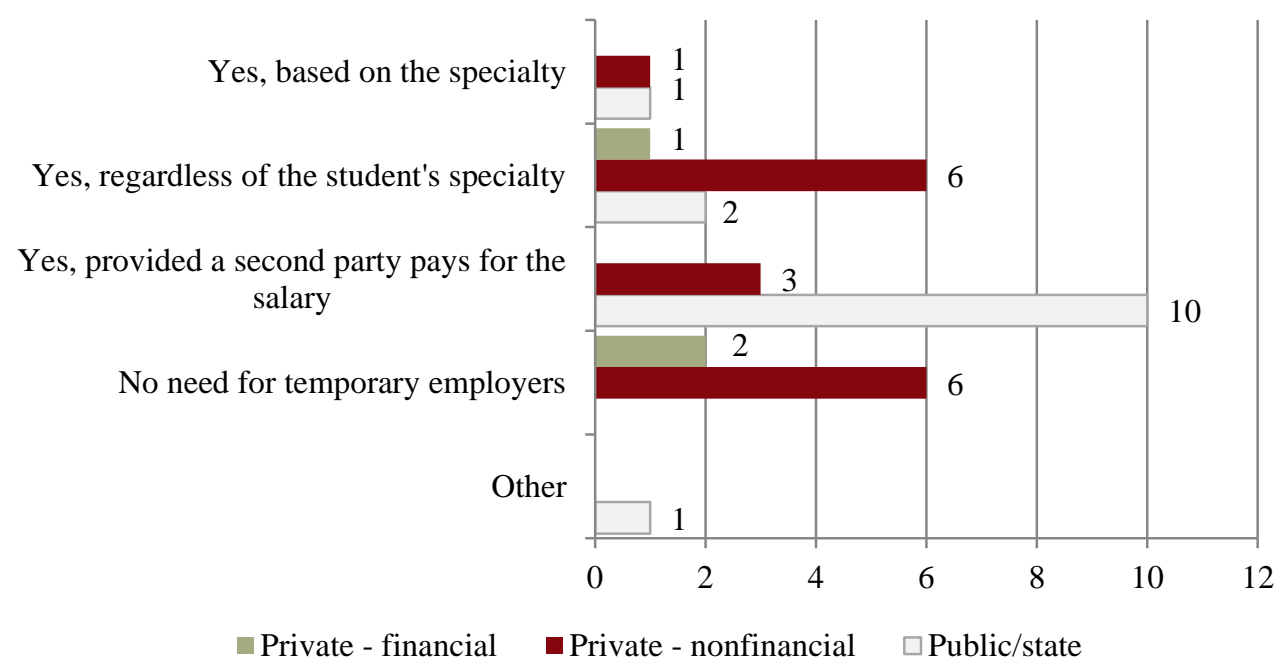

Figure 9. Question 7. Would you provide job opportunities for students from the FE of TrU during the course of their tuition? /Respondents: 34 (100\%)/

The primary obstacle before providing employment to students during the course of their tuition is probably the impossibility of firms/institutions to fund this activity. In the private and the public sector, such opportunities can be provided, if payment is covered by another institution (Figure 9). We believe that this issue can be overcome at this stage through clearly expressed will for mutual participation of education institutions and the ones from practice in projects per the OP of the EU, such as OPHRD and OPAC. 
General economic knowledge and qualifications

Specialized training for the specific major

Specialized qualification for the job offered

Other
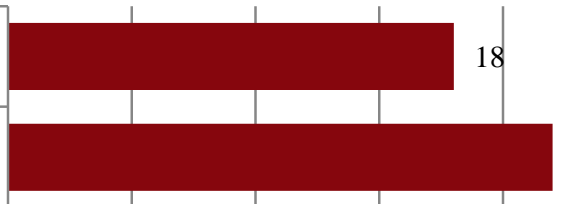

22

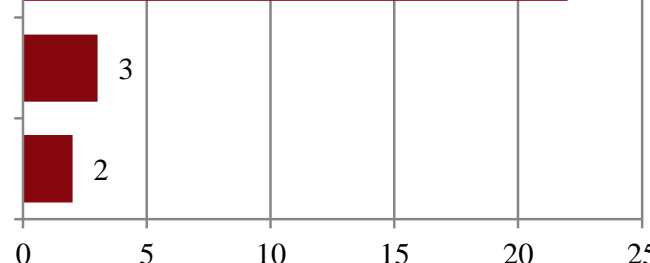

Figure 10. Question 8. What training did you expect from the students who have graduated from the FE of TrU? /Respondents: $34(100 \%) /$

The expectations of institutions and firms for the training of future specialists with higher education (Figure 10) generally correspond to the logic of the currently existing curricula and programmes at the higher education institutions, particularly the FE - broad-profile economic training during the first and second year and specialised disciplines in the major during the third and fourth year for the educationalqualification degree of "Bachelor," with the acquisition of a narrow specialisation during the Master's degree studies.

Firms' pronounced interest towards cooperation has a role in the higher practical orientation of the tuition (Figures 11 and 12).

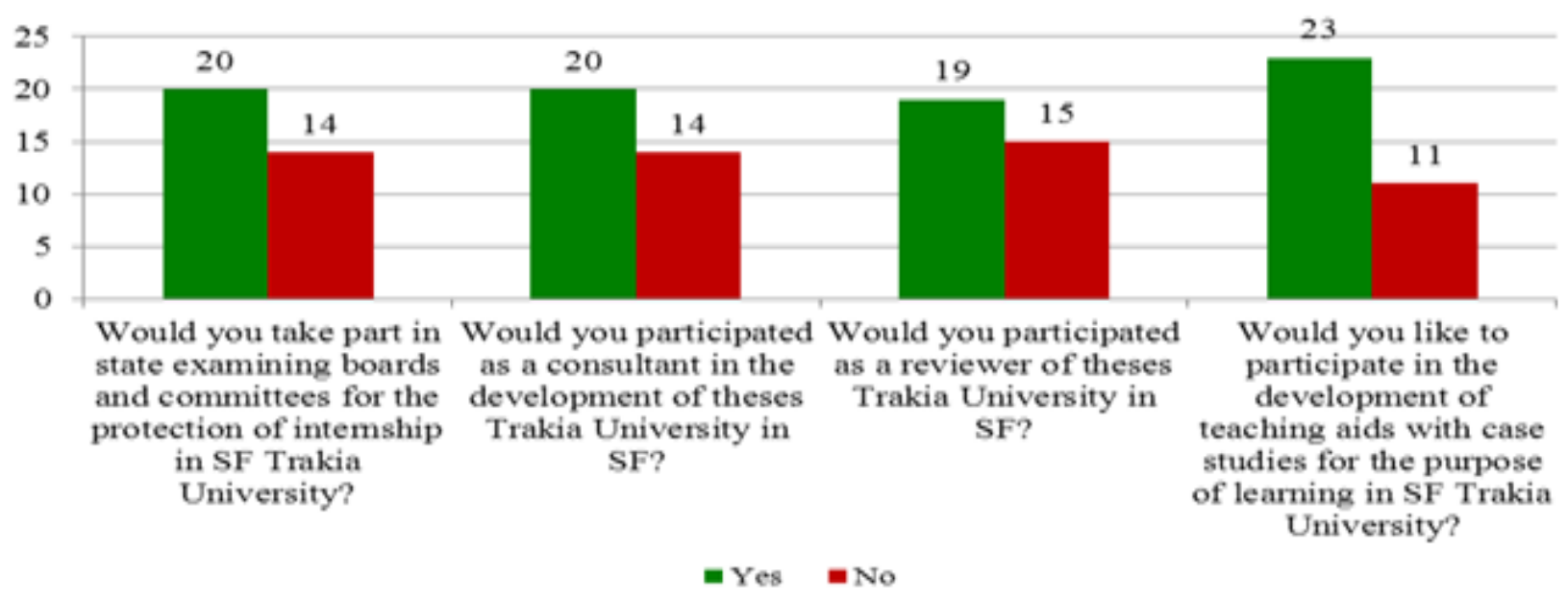

Figure 11. Readiness of employers and specialists from practice to participate under various forms of educational activity /The respondents for the four questions were 34 (100\%)/

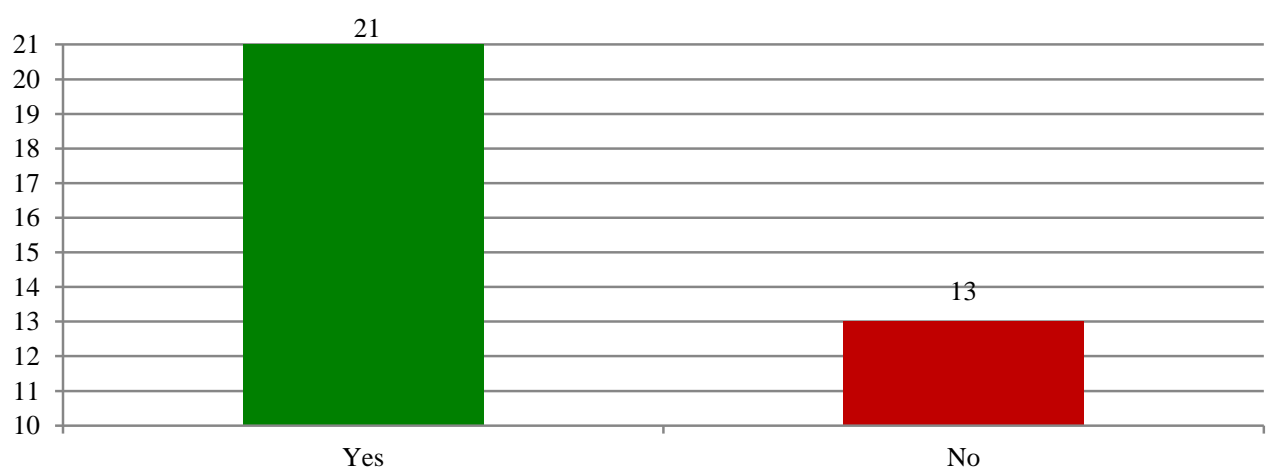

Figure 12. Question 13. Would you participate in the conducting of a seminar on a specific topic for the students of the FE at TrU? /Respondents: 34 (100\%)/ 
Public/state

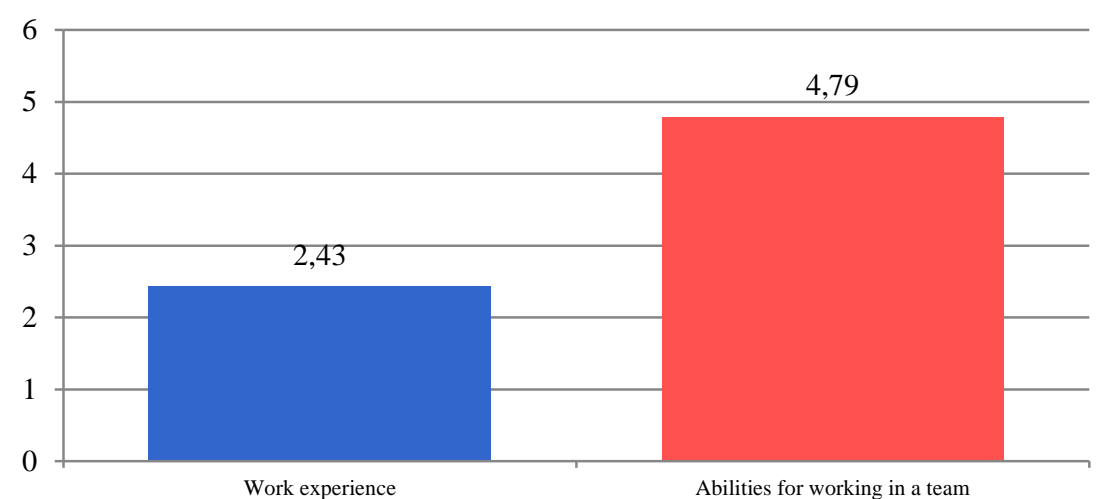

Private - nonfinancial

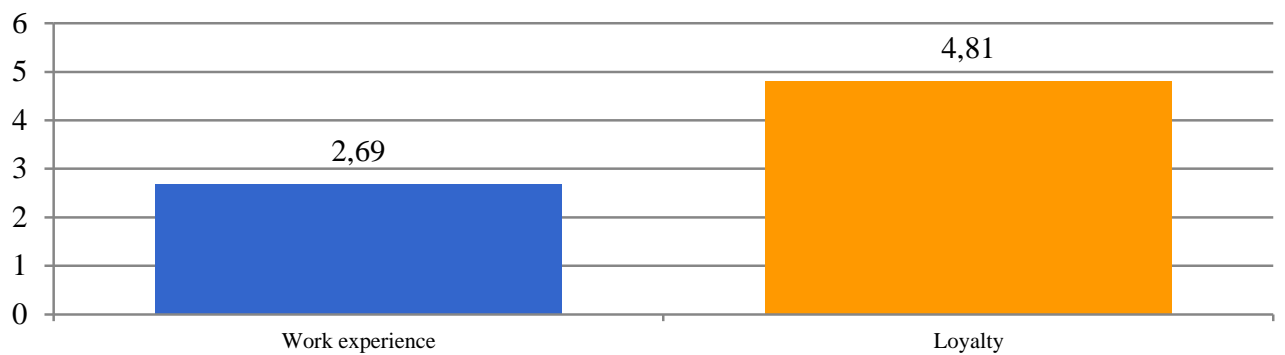

Private - financial

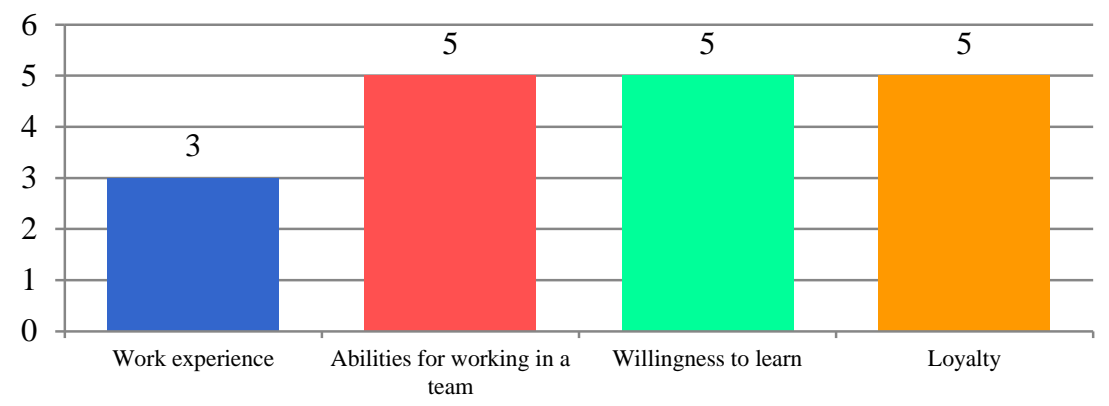

Figure 13. Question 18. On a scale of 1 to 5, determine how important to you is each of the listed criteria for the selection of specialist-economists for your firm/institution, with "1" signifying "not important" and "5" meaning "it is very important." /Respondents: 34 (100\%)/

Most of the employers' criteria in the selection of staff (Figure 13) are within the type of the socalled soft skills. A study by NBU indicated that these skills are very lacking among most newly hired employees (5).

Question 22. On a scale of 1 to 5, determine to what extent the content of the disciplines (curricula) satisfies the needs of practice, with "1" meaning "does not satisfy" and " 5 " meaning "fully satisfies". /Respondents: 30 $(88.24 \%) /$

\section{RESULTS}

- Over $50 \%$ of the respondents exhibited interest towards the curricula of the presented disciplines;

- The greatest interest (over $1 / 3$ of the respondents) was shown towards the following disciplines:

- Planning and prediction;

- Entrepreneurship;

- Financial-business analysis;

- Human resources;

- Company accounting; 
- Marketing;

- Finance;

- Local and regional development;

- Quality management;

- Development and management of projects for

regional economic growth;

- Financial management;

- Agricultural economics;

- Commercial transactions.

- The mean grade of the listed disciplines was 3.73

General suggestions /Respondents: 24

$(70.59 \%) /:$

Recommendations for the knowledge and skills of graduating students:

- Legal knowledge and usage of the legal system;

- Foreign language knowledge;

- Being informed and up-to-date;

- Administrative skills (written and oral communication with institutions and people, minute-taking skills);

- Presentation and position defence skills (including for participation in a job interview);

- Teamwork skills;

- Information selection skills;

- Analysis and statement preparation skills;

- Objective process evaluation skills;

- Sale skills;

- Managerial decision-making skills;

- Master's students from the managerial majors should be trained in leadership skills.

\section{General recommendations for the training of economists:}

- Students should be in touch with companies during the course of their studies (including weekly visits);

- Find ways to pay companies when they train interns;

- Annual internship at a firm, corresponding to the major;

- Complement disciplines with examples from practice, as well as case studies to be solved by the students;

- AT least one lecture in a given course should be conducted by a specialist from practice;

- Study practice should become a part of course engagement (as extra-auditorium activities);

- Greater attention to the practical part in auditorium activities (incl. computer skills, foreign language);
- More hours for projects development;

- Updating of textbooks and study aids, in accordance with the contemporary conditions and the needs of practice;

- Include more examples from high-priority sectors on a national and regional level;

- Give more attention to control systems within the managerial process;

- Implement disciplinary upgrading;

- Review all disciplines after the second year, which are common for the three majors;

- Implement a "Social Entrepreneurship" Master's programme;

- Implement a "Business Administration" Master's programme.

\section{Additional suggestions:}

- Improvement of the relations between business and the university, in the field of student education, as well as in improving the qualification of company staff;

- Form a team for mutual work on plan and programme documents for the region;

- Organise annual courses for post-graduation training in "Human Resource Management," "Marketing," "Management;"

- Implement remote form of tuition.

Questions 24 and 25. Your suggestions for new disciplines and topics /Respondents: 19 (55.88 $\%) /$

More than 50 suggestions were given for changes in the studied disciplines:

- Suggestions for changes in the name or character of some disciplines in all majors. They are primarily related to linking the name with a specific major;

- Proposals for new disciplines (depending on the major);

- There were also a few suggestions about improving the study content of some disciplines.

The responses from Question 26 (Figure 14) definitively indicate the desire for cooperation between the university and the institutions from practice. Yet, compared to the responses from Questions 6 and 7 (Figures 8 and 9), which show the financial obstacles before this, and the results from (Figures 11 and 12) regarding the firms' readiness to participate in the student education process, the following summarisation can be made:

Business firms and public institutions prefer to provide more training information, to share experience, consult the young people, yet only 
within the auditorium classes and other academic activities designated for this purpose in their educational degree. With regard to providing stimuli and opportunities to the students to participate within the production process itself, for temporary employment and selection of new specialists during the course of tuition, and
GAYDARDZHIEVA V., et al.

especially toward payment for student labour, there is hesitation and reluctance to expend financial resources. It is assumed that financial obstacles have an objective character, yet it can be claimed that investments aimed at improving education and staff qualification is almost always profitable.

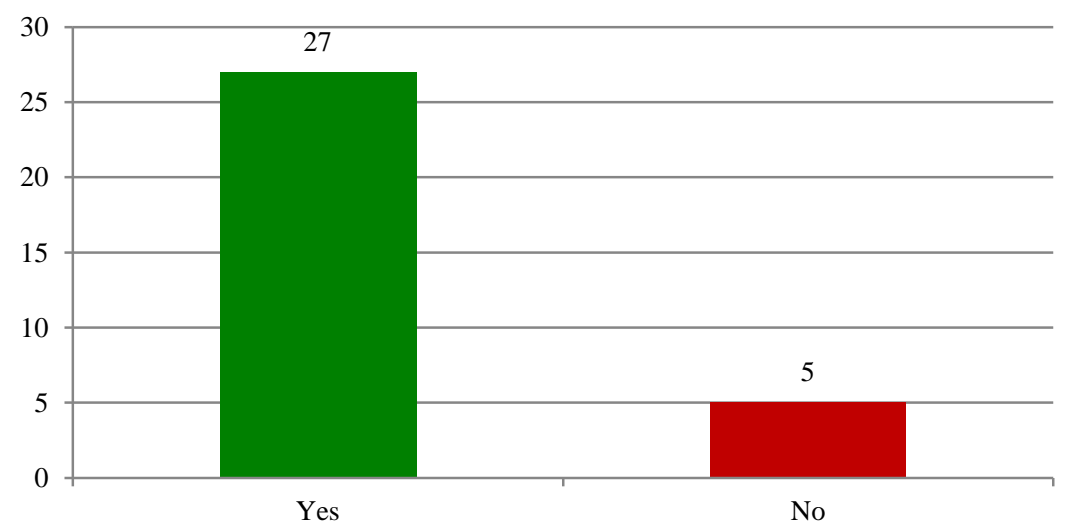

Figure 14. Question 26. Would you support the concluding of a bilateral agreement between your firm an the Faculty of Economics at TrU? /Respondents: 32 (94.12\%)/

Within the conducted survey, the respondents gave suggestions about scientific research, which would really deal with the solution of the reviewed problems:

\section{Topics for scientific projects proposed by business and practice:}

$>$ Analysis of the means of managing the measures per PRSR

$>$ Development of a mechanism for supporting backward regions (municipalities) with the goal of reducing inter-regional differences

$>$ An economic yearbook of the Stara Zagora region

$>$ Why do firms not prefer to apply for funding programmes? What mechanisms can be proposed to stimulate such participation?

$>$ Expenses optimisation

$>$ Determining remuneration and employee motivation

$>$ Standardisation and control in tourism

$>$ Project development and management

$>$ Firm certification

$>$ Organising and managing a firm

\section{MEASURES AND RECOMMENDATIONS:}

The conducted studies and analyses can lead to the following conclusions and summaries:

- If necessary, determining the directions for updating curricula and study programmes;
- $\quad$ Finding the most effective forms for quality practical preparation of the students;

- Creating prerequisites for a better interaction within the "triangle of knowledge" (education - research practice) and for transfer of knowledge in favour of the local economy and society;

- Building a sustainable and efficient partnership between the administration of the Faculty of Economics and employers in the Stara Zagora region is necessary and should be based upon working mechanisms for cooperation;

- Adapting the curricula and study programmes in the vocational orientations of "Economics" and "Administration and management" at the Faculty of Economics of Trakia University should be aimed at the needs of business and practice, as well as European qualification standards, in order to improve the suitability for employment and entrepreneurship of the specialists trained at the Faculty of Economics;

- Better interaction within the "triangle of knowledge" (education - research practice) via translation of results from scientific and applied science studies of the Faculty of Economics into the curricula, and through a connection between the scientific research sector of the Faculty of Economics and the needs of business and practice; 
- Improvement of the quality of educational services at the Faculty of Economics by applying contemporary interactive methods and means of ICT in the study process;

- The activities planned for the project are in unison with the measures included in Regulation 1081/2006 of the European Parliament and the Council with regard to the European Social Fund, for influence within the scope of the goal "regional competitiveness and employment" and the goal "approximation," leading to economic growth and improvement of the quality and productivity of labour through an increase in the adaptability of the labour force and of companies, human capital growth, extending access to job positions and increasing the participation of the labour market, as well as through popularising of reform partnerships.

\section{REFERENCES}

1. MEI, Regional profiles, Indications for development, http://www.regionalprofiles.bg/var/docs/Pro files-2012/Stara_Zagora_.pdf, p. 137, 2012

2. Primary results from the analysis of the social-economic development of the regions in Bulgaria, MRD,

www.mrrb.government.bg, 04 July 2012

3. Genova, J. Sociology for students in social and economic sciences, administration and management., UE „Paisiy Hilendarski," Pd., 2010

4. Likert, R. A Technique for the Measurement of Attitudes. Archives of Psychology, pp. 140: 1-55, 1932

5. Centre for quality, evaluation and accreditation, NBU, Survey among employers, 2010-2011 